\title{
Produção do girassol e teor de óleo nos aquênios em função da temperatura do ar, precipitação pluvial e radiação solar
}

\author{
Yield of sunflower and oil seed content as a function of air temperature, rainfall and solar radiation
}

\author{
Giovani Luiz Thomaz I Jeferson Zagonel' ${ }^{\mathrm{II}}$ Luiz Osvaldo Colasante ${ }^{\mathrm{III}}$ Ranieri Ramos Nogueira
}

\section{RESUMO}

O presente estudo teve o objetivo de avaliar o efeito da temperatura do ar, precipitação pluvial e radiação solar, ocorridos em cada fase fenológica da cultura do girassol, na produção de aquênios, no teor de óleo dos aquênios e na produção de óleo do girassol. Foram conduzidos dez experimentos em intervalos de 20 dias, com início em 30/07/ 2007 e término em 28/01/2008. Cada experimento constituiu uma época de semeadura. Para verificar a normalidade dos erros e homogeneidade das variâncias, inicialmente, realizouse uma análise individual por experimento para, em seguida, realizar análise conjunta. O delineamento experimental utilizado foi o de blocos ao acaso com quatro tratamentos (cultivares) e quatro repetições, em cada época de semeadura. Houve interação entre épocas de semeadura e cultivares para todas as variáveis estudadas. Foram feitas análises de correlação entre as variáveis meteorológicas e as de produção do girassol. A produção de aquênios, teor de óleo e produção de óleo nas cultivares de girassol foram mais elevados quando ocorreram temperaturas mais baixas na fase vegetativa, maiores precipitações pluviais na floração e maiores índices de radiação solar na fase vegetativa e de enchimento de aquênios.

Palavras-chave: Helianthus annuus, rendimento de aquênios, rendimento de óleo, fase fenológica.

\section{ABSTRACT}

The objective of this research was to evaluate the effect of air temperature, rainfall and solar radiation occurring during each phonological phase of the sunflower crop, on yield of achenes, on oil content of achenes and on oil yield in sunflower. Ten experiments were carried out at Ponta Grossa,
PR, Brazil, with intervals of 20 days, beginning on July 30, 2007 and finishing on January 28, 2008. Each sowing time constituted an experiment. The experiments were arranged in a randomized complete block design, with four treatments (cultivars) and four replicates. It was performed the analysis of variance of each experiment separately and, after that, the joint analysis of all experiments. There was interaction between sowing date and cultivars for all the studied variables. Correlation analysis between meteorological and yield variables of sunflower were performed. The achene yield, oil content and oil yield in sunflower cultivars were higher when there were lower temperatures in the vegetative phase, higher rainfall at flowering and higher levels of radiation in the vegetative and filling of achenes phase.

Key words: Helianthus annuus, yield of achenes, oil yield, phenological period.

\section{INTRODUÇÃO}

O Programa Nacional do Biodiesel, criado pela lei 11.097/2005, determina que, a partir do ano de 2013, será obrigatória a adição de 5\% de biodiesel ao óleo diesel consumido no Brasil, criando um mercado de cerca de 2,5 bilhões de litros de biodiesel ao ano, tornando necessário o aumento da oferta global de óleos vegetais nos próximos anos. Dentre as plantas oleaginosas com potencial para a produção de biodiesel, o girassol apresenta as seguintes características desejáveis: elevado teor de óleo, cultivo com menor

IInstituto Agronômico do Paraná (IAPAR), CP 129, 84001-970, Ponta Grossa, PR, Brasil. E-mail: gthomaz@iapar.br. *Autor para correspondência.

IIUniversidade Estadual da Ponta Grossa (UEPG), Ponta Grossa, PR, Brasil.

IIIIAPAR, Londrina, PR, Brasil. 
exigência hídrica, bom potencial produtivo e possibilidade de adequar-se em sistemas de produção sem competir com a cultura principal (GAZZONI, 2005). A produção de aquênios, o teor de óleo dos aquênios e a produção de óleo do girassol dependem da temperatura do ar, da precipitação pluvial e da radiação solar incidente na cultura no decorrer do seu ciclo (AGUIRREZÁBAL et at., 2001).

Vários autores citam a importância da radiação solar na fase de enchimento de aquênios, da disponibilidade de água durante todo o ciclo da cultura, e a influência que a temperatura do ar exerce na duração das fases de desenvolvimento e ciclo total da cultura. No entanto, há poucos estudos que analisam estas variáveis meteorológicas ocorridas separadamente em cada fase de desenvolvimento da cultura e seus efeitos na produção do girassol.

O objetivo deste trabalho foi estudar o efeito da temperatura média do ar, precipitação pluvial e radiação solar, ocorridos em cada fase fenológica da cultura do girassol, na produção de aquênios, no teor de óleo dos aquênios e na produção de óleo.

\section{MATERIAL E MÉTODOS}

Os experimentos foram instalados na Estação Experimental do IAPAR em Ponta Grossa, PR, localizada nas coordenadas $25^{\circ} 09^{\prime} 50^{\prime \prime}$ S e $50^{\circ} 09^{\prime} 10^{\prime \prime}$ $\mathrm{W}$ e altitude de 823 metros. O clima é classificado segundo Köppen como Cfb, ou seja, clima temperado típico, com temperatura média no mês mais frio abaixo de $18^{\circ} \mathrm{C}$ (mesotérmico), com verões frescos, temperatura média no mês mais quente abaixo de $22^{\circ} \mathrm{C}$ e sem estação seca definida (IAPAR, 2009). A precipitação média anual é de $1.600 \mathrm{~mm}$ a $1.800 \mathrm{~mm}$, com o trimestre mais chuvoso (dezembro, janeiro e fevereiro) com média de $500 \mathrm{~mm}$ a $600 \mathrm{~mm}$ e o mais seco (junho, julho e agosto) com média de $250 \mathrm{~mm}$ a 350mm.

O solo do local do experimento é classificado como LATOSSOLO VERMELHO Distrófico, textura argilosa, fase relevo suave ondulado (SANTOS et al., 2006). A análise química do solo da camada de zero a $0,2 \mathrm{~m}$, feita antes da implantação dos experimentos, resultou em 2,1 $\mathrm{mg} \mathrm{dm}^{-3}$ de $\mathrm{P}$ (Mehlich); 28,85 $\mathrm{g} \mathrm{dm}^{-3} \mathrm{de}$ $\mathrm{C}$; pH 5,2; zero de saturação por $\mathrm{Al} ; 4,9 \mathrm{cmol} \mathrm{dm}^{-3} \mathrm{de}$ Ca; 3,3cmol dm ${ }^{-3}$ de Mg; 0,23cmol dm $\mathrm{dm}^{-3}$ de K(Mehlich) e saturação por bases de $63 \%$.

O delineamento experimental foi de blocos ao acaso, com quatro tratamentos (cultivares Catissol, M734, Hélio 250 e Aguará 4) e quatro repetições. Em intervalos de 20 dias, um novo experimento foi implantado, constituindo as épocas de semeadura, denominadas E1, E2, E3, E4, E5, E6, E7, E8, E9 e E10, semeadas, respectivamente, nos dias 30/07/2007, 17/ 08/2007, 05/09/2007, 24/09/2007, 17/10/2007, 07/11/2007, 27/11/2007, 18/12/2007, 07/01/2008 e 28/01/2008. Cada parcela foi constituída de quatro fileiras de plantas de $7,0 \mathrm{~m}$ de comprimento espaçadas de $0,7 \mathrm{~m}$. A densidade foi de 3,3 plantas por metro linear, equivalente a 47.142,8 plantas ha-1 ${ }^{-1}$ As avaliações foram feitas nas duas fileiras centrais de cada parcela, desprezando-se $0,5 \mathrm{~m}$ em cada extremidade. Assim, a área útil avaliada de cada parcela foi de $8,4 \mathrm{~m}^{2}$.

No momento da semeadura de cada época, foram distribuídos e incorporados manualmente nos sulcos $10 \mathrm{~kg} \mathrm{ha}^{-1}$ de nitrogênio, $60 \mathrm{~kg} \mathrm{ha}^{-1} \mathrm{de}_{2} \mathrm{O}_{5}$ e $60 \mathrm{~kg}$ ha-1 de $\mathrm{K}_{2} \mathrm{O}$, e a adubação de cobertura foi feita no estádio de desenvolvimento V-6 (CASTIGLIONI et al., 1997), quando foram aplicados manualmente $30 \mathrm{~kg} \mathrm{ha}^{-1}$ de $\mathrm{N}$, na forma de sulfato de amônio, e $2 \mathrm{~kg} \mathrm{ha}^{-1}$ de boro, na forma de bórax. Assim, o total aplicado de nutrientes por ha foi $40 \mathrm{~kg}$ de $\mathrm{N}, 60 \mathrm{~kg}$ de $\mathrm{P}_{2} \mathrm{O}_{5}, 60 \mathrm{~kg}$ de $\mathrm{K}_{2} \mathrm{O}$ e $2 \mathrm{~kg}$ de B.

A colheita, a debulha e a limpeza dos aquênios foram feitas manualmente, e a produção de aquênios foi calculada pela massa da parcela, corrigindo-se para umidade padrão de $11 \%$ e extrapolado para $\mathrm{kg} \mathrm{ha}^{-1}$. A extração do óleo foi realizada pelo método de Soxhlet, utilizando-se como solvente o éter de petróleo, e calculando-se, em seguida, os resultados em porcentagem base seca. A produção de óleo foi calculada utilizando-se o teor de óleo dos aquênios e a produção de aquênios. Como o teor de óleo foi calculado considerando-se $100 \%$ de massa seca (base seca) o valor foi corrigido para $11 \%$ de umidade, multiplicando-se pelo fator 0,89 . O valor foi expresso em kg ha ${ }^{-1}$.

Inicialmente, efetuou-se a análise de variância de cada experimento, isto é, em cada época de semeadura. Após, realizou-se a análise conjunta dos experimentos (PIMENTEL-GOMES \& GARCIA, 2002), com objetivo de testar a interação entre épocas e cultivares.

Para as análises de variância e comparação entre médias, utilizou-se o programa estatístico SISVAR (FERREIRA, 2003). As médias foram comparadas pelo teste de Scott-Knott, a 5\% de probabilidade. Estas análises foram feitas para verificar a normalidade dos erros e homogeneidade das variâncias e obter os valores médios das variáveis de rendimento, os quais foram submetidos a análises de correlação de Pearson com as variáveis meteorológicas ocorridas em cada fase de desenvolvimento do girassol. A interpretação dos coeficientes de correlação de Pearson (r) foi feita utilizando-se as faixas de valores propostas por SHIKAMURA (2008), que estabelece de 0 a 0,19 como 
"muito fraca"; 0,20 a 0,39 como "fraca"; 0,40 a 0,69 como "moderada"; 0,70 a 0,89 como "forte" e 0,90 a 1,00 como "muito forte".

\section{RESULTADOS E DISCUSSÃO}

Os valores da precipitação pluvial, temperatura média do ar e radiação solar ocorridas nas épocas de semeaduras e fases fenológicas estão nas tabela 1. Na tabela 2, estão os dados de produtividade de aquênios, teor de óleo e rendimento de óleo em cada época de semeadura, considerando-se a média das cultivares. Através da análise de variância, verificou-se que houve interação entre épocas de semeadura e cultivares para todas as variáveis estudadas.

Verificou-se uma correlação forte entre a precipitação pluvial ocorrida no período da floração $\left(\mathrm{R}_{4}-\mathrm{R}_{6}\right)$ com a produção de aquênios ( $\left.\mathrm{r}=0,73\right)$, teor de óleo $(\mathrm{r}=0,72)$ e produção de óleo $(\mathrm{r}=0,72)$ (Tabela 3$)$, corroborando diversos autores (AGUIRREZÁBAL et al., 2001; MERCAU et al., 2001; ERDEM \& DELIBAS, 2003; CASTRO \& FARIAS, 2005; CASTRO et al., 2006) que citam a importância da disponibilidade hídrica neste período.

Houve correlação negativa forte entre a temperatura média do ar no período emergência-broto floral $\left(\mathrm{VE}-\mathrm{R}_{1}\right)$ com a produção de aquênios $(\mathrm{r}=-0,77)$, teor de óleo $(\mathrm{r}=-0,87)$ e produção de óleo $(\mathrm{r}=-0,81)$, indicando uma associação de rendimentos mais altos a temperaturas mais baixas na fase vegetativa, para a amplitude de temperatura ocorrida durante os experimentos (Figura 1). Este resultado é discordante dos obtidos por SMIDERLE et al. (2005), que obtiveram altos rendimentos em semeaduras de janeiro em Roraima (sob irrigação), onde ocorrem altas temperaturas do ar. Em outro trabalho realizado em Roraima, SMIDERLE et al. (2002) concluíram que as altas temperaturas reduziram o ciclo de deselvolvimento das cultivares, porém os teores de óleo não foram afetados com a mesma intensidade. Entretanto, os autores não analisaram separadamente as temperaturas ocorridas em cada fase de desenvolvimento da cultura.

Alguns autores associam o teor de óleo com temperatura do ar no período de desenvolvimento dos aquênios. HARRIS et al. (1978) observaram que temperatura alta durante o enchimento de aquênios é associada com uma redução na produção de óleo total, porém este efeito pode se confundir com a variação de outros fatores ambientais. CASTRO \& FARIAS (2005) citam que temperaturas acima de $35^{\circ} \mathrm{C}$ reduzem o teor de óleo, porém não ocorreram tais temperaturas nos experimentos do presente trabalho. UNGARO et al. (1997), trabalhando com três cultivares, apontaram como fator de redução no conteúdo de óleo tanto as temperaturas altas quanto as baixas no período

Tabela 1 - Temperatura média do ar, precipitação pluvial acumulada e radiação solar acumulada para as fases fenológicas das cultivares em cada época de semeadura. IAPAR, Estação Experimental de Ponta Grossa-PR, 2008.

\begin{tabular}{|c|c|c|c|c|c|c|c|c|c|c|c|}
\hline \multirow{2}{*}{$\begin{array}{l}\text { Elemento } \\
\text { meteorológ. }\end{array}$} & \multirow{2}{*}{$\begin{array}{c}\text { Fase } \\
\text { Fenológ. }\end{array}$} & \multicolumn{10}{|c|}{ 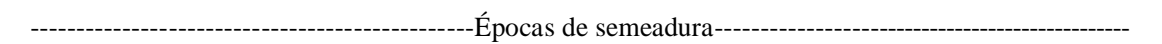 } \\
\hline & & E1 & E2 & E3 & E4 & E5 & E6 & E7 & E8 & E9 & E10 \\
\hline \multirow{4}{*}{$\begin{array}{l}\text { Temperatura } \\
\text { média do ar }\left({ }^{\circ} \mathrm{C}\right)\end{array}$} & VE-R1 & 18,5 & 19,3 & 20,1 & 20,8 & 21,1 & 21,2 & 22,3 & 21,7 & 21,1 & 21,8 \\
\hline & R1-R4 & 20,2 & 21,1 & 20,6 & 20,9 & 22,2 & 22,3 & 21,3 & 21,1 & 21,8 & 20,8 \\
\hline & R4-R6 & 21,3 & 20,6 & 20,8 & 22,0 & 22,8 & 21,3 & 20,6 & 22,1 & 21,2 & 20,0 \\
\hline & R6-R9 & 20,4 & 21,0 & 22,2 & 22,2 & 21,5 & 21,1 & 21,9 & 21,6 & 19,9 & 17,5 \\
\hline \multirow{4}{*}{$\begin{array}{l}\text { Precipitação } \\
\text { pluvial (mm) }\end{array}$} & VE-R1 & 62 & 56 & 94 & 180 & 221 & 305 & 281 & 184 & 217 & 185 \\
\hline & R1-R4 & 50 & 97 & 194 & 37 & 187 & 143 & 87 & 112 & 44 & 88 \\
\hline & R4-R6 & 149 & 120 & 97 & 173 & 94 & 79 & 102 & 28 & 73 & 76 \\
\hline & R6-R9 & 55 & 135 & 117 & 108 & 80 & 128 & 50 & 76 & 90 & 129 \\
\hline \multirow{4}{*}{$\begin{array}{l}\text { Radiação solar } \\
\left(\mathrm{W} \mathrm{m}^{-2}\right)\end{array}$} & VE-R1 & 18933 & 17039 & 15552 & 16050 & 16050 & 16117 & 14800 & 12501 & 11671 & 14358 \\
\hline & R1-R4 & 7153 & 7000 & 8900 & 9810 & 10639 & 9055 & 7070 & 7884 & 8590 & 6380 \\
\hline & R4-R6 & 5317 & 4145 & 5982 & 4864 & 3773 & 4599 & 4884 & 4677 & 3227 & 3958 \\
\hline & R6-R9 & 13498 & 13642 & 12020 & 11763 & 10219 & 10155 & 7280 & 6391 & 7166 & 5052 \\
\hline
\end{tabular}

$\mathrm{VE}-\mathrm{R}_{1}$ : fase vegetativa - refere-se ao período da emergência ao aparecimento do broto floral;

$\mathrm{R}_{1}-\mathrm{R}_{4}$ : é o período do aparecimento do broto floral à floração inicial;

$\mathrm{R}_{4}-\mathrm{R}_{6}$ : floração - refere-se ao período da floração inicial ao fim da floração;

$\mathrm{R}_{6}-\mathrm{R}_{9}$ : enchimento de aquênios - refere-se ao período do fim da floração à maturação fisiológica.

Ciência Rural, v.42, n.8, ago, 2012. 
Tabela 2 - Valores médios de produção de aquênio, teor de óleo e produção de óleo das cultivares em cada época de semeadura. IAPAR, Estação Experimental de Ponta Grossa-PR, 2008.

\begin{tabular}{|c|c|c|c|c|c|c|c|c|c|c|}
\hline & E1 & E2 & E3 & E4 & E5 & E6 & E7 & E8 & E9 & E10 \\
\hline Prod. aqu. (kg ha ${ }^{-1}$ ) & 1964 & 2025 & 2154 & 1982 & 1599 & 1360 & 1264 & 1138 & 1056 & 1044 \\
\hline Teor de óleo (\%) & 47,6 & 47,1 & 45,5 & 45,2 & 43,4 & 42,6 & 39,7 & 39,3 & 38,8 & 37,6 \\
\hline Prod. óleo (kg ha $\left.{ }^{-1}\right)$ & 823 & 846 & 878 & 791 & 619 & 510 & 439 & 403 & 365 & 357 \\
\hline
\end{tabular}

florescimento-maturação, com respostas distintas de acordo com o genótipo. No presente trabalho, as temperaturas ocorridas após o aparecimento do botão floral até a maturação fisiológica apresentaram coeficientes de correlação variando de fraco a moderado com o teor de óleo, produção de aquênios e de óleo, indicando baixa associação destas variáveis de rendimento com a temperatura ocorrida após o período vegetativo, ou que a amplitude das temperaturas ocorridas (Figura 1) não foram acentuadas a ponto de causarem os efeitos observados pelos autores supracitados.

Das variáveis meteorológicas estudadas, a radiação solar ocorrida no enchimento de aquênios $\left(\mathrm{R}_{6}\right.$ $\mathrm{R}_{\mathrm{q}}$ ) apresentou os maiores coeficientes de correlação com produção de aquênios $(r=0,93)$, teor de óleo $(r=0,99)$ e produção de óleo $(r=0,93)$. Este resultado corrobora os obtidos por AGUIRREZÁBAL et al. (2003), em que uma redução da radiação fotossinteticamente ativa interceptada durante a fase de enchimento de aquênios afetou o peso das sementes e o teor de óleo. Da mesma forma, AGUIRREZÁBAL et al. (2001) afirmam que a maior parte dos carboidratos utilizados para a síntese de óleo e enchimento de aquênios provém da fotossíntese contemporânea a tais processos, e que o percentual de óleo é definido durante a etapa de enchimento dos aquênios. VEGA \& HALL (2002) constataram que o rendimento é fortemente associado com a duração do período de enchimento de aquênios e com a área foliar existente, fatores que determinam a quantidade de radiação solar interceptada neste período. IZQUIERDO et al. (2008) e DOSIO et al. (2000) constataram que a concentração de óleo é menor em épocas de semeaduras mais tardias, quando ocorre uma diminuição da quantidade de radiação solar devido à redução do comprimento do dia. No presente trabalho,

Tabela 3 - Coeficientes de correlação obtidos entre a temperatura média do ar, precipitação pluvial e radiação solar e os valores médios de produção de aquênios, teor de óleo e produção de óleo das cultivares em cada época de semeadura. IAPAR, Estação Experimental de Ponta Grossa-PR, 2008.

\begin{tabular}{|c|c|c|c|c|}
\hline Elemento meteorológico & Fase fenológica & Produção de aquênios & Teor de óleo & Produção de óleo \\
\hline \multirow{4}{*}{ Temperatura média do ar } & VE-R1 & $-0,77$ & $-0,87$ & $-0,81$ \\
\hline & R1-R4 & $-0,44$ & $-0,33$ & $-0,45$ \\
\hline & R4-R6 & 0,10 & 0,17 & 0,09 \\
\hline & R6-R9 & 0,50 & 0,45 & 0,47 \\
\hline \multirow{4}{*}{ Precipitação pluvial } & VE-R1 & $-0,69$ & $-0,65$ & $-0,72$ \\
\hline & R1-R4 & 0,16 & 0,10 & 0,15 \\
\hline & R4-R6 & 0,73 & 0,72 & 0,72 \\
\hline & R6-R9 & 0,16 & 0,10 & 0,17 \\
\hline \multirow{4}{*}{ Radiação solar } & VE-R1 & 0,75 & 0,84 & 0,76 \\
\hline & R1-R4 & 0,23 & 0,21 & 0,20 \\
\hline & R4-R6 & 0,60 & 0,49 & 0,58 \\
\hline & R6-R9 & 0,93 & 0,99 & 0,93 \\
\hline
\end{tabular}

$\mathrm{VE}-\mathrm{R}_{1}$ : fase vegetativa - refere-se ao período da emergência ao aparecimento do broto floral;

$\mathrm{R}_{1}-\mathrm{R}_{4}$ : é o período do aparecimento do broto floral à floração inicial;

$\mathrm{R}_{4}-\mathrm{R}_{6}$ : floração - refere-se ao período da floração inicial ao fim da floração;

$\mathrm{R}_{6}-\mathrm{R}_{9}$ : enchimento de aquênios - refere-se ao período do fim da floração á maturação fisiológica.

Ciência Rural, v.42, n.8, ago, 2012. 


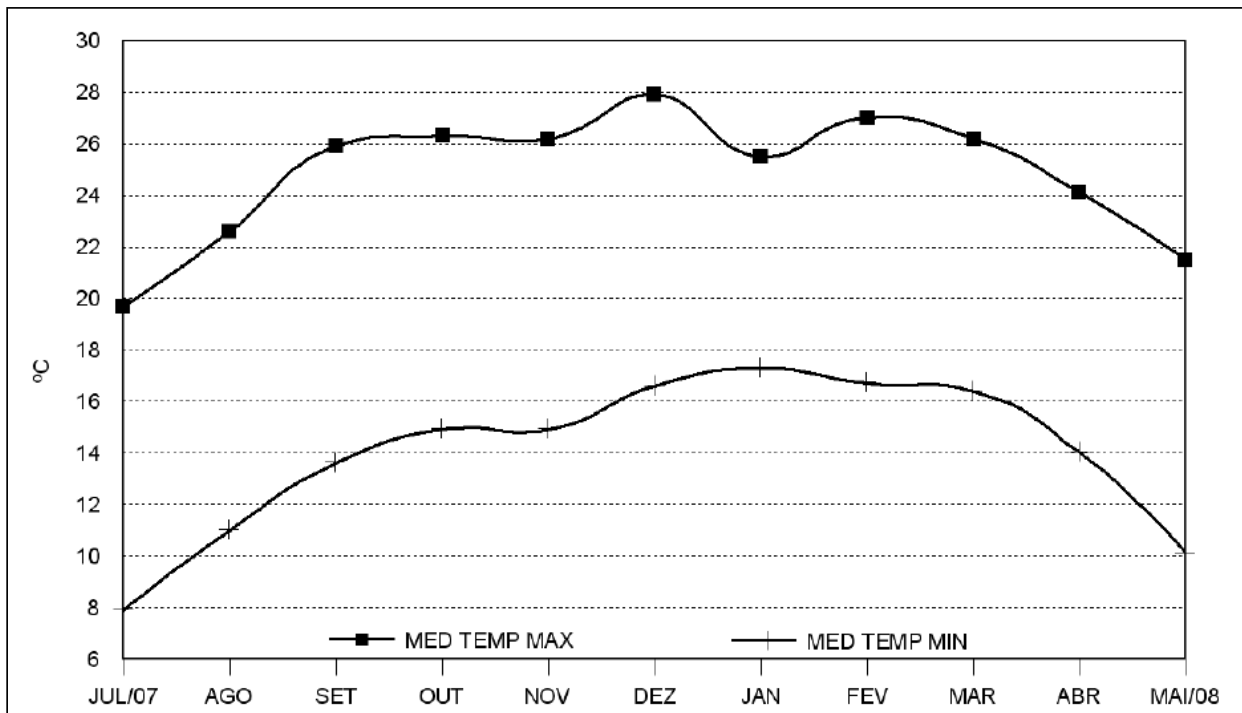

Figura 1 - Médias mensais das temperaturas máximas e mínimas no decorrer dos experimentos. IAPAR, Estação Experimental de Ponta Grossa-PR, 2008.

além do período de enchimento de aquênios, as variáveis de rendimento tiveram associação com a radiação solar ocorrida também no período vegetativo, com coeficientes de correlação forte na produção de aquênios $(\mathrm{r}=0,75)$, teor de óleo $(\mathrm{r}=0,84)$ e produção de óleo $(\mathrm{r}=0,76)$.

\section{CONCLUSÃO}

Dentro dos valores das variáveis meteorológicas ocorridos durante o trabalho, a produção de aquênios, teor de óleo dos aquênios e produção de óleo do girassol são mais elevados quando ocorrem temperaturas mais baixas no período vegetativo, maiores precipitações pluviais na floração e maiores índices de radiação solar no período vegetativo e de enchimento de aquênios.

\section{AGRADECIMENTOS}

Ao Instituto Agronômico do Paraná (IAPAR) e à Secretaria de Estado da Ciência, Tecnologia e Ensino Superior (SETI), pela estrutura e apoio financeiro para a realização dos trabalhos.

\section{REFERÊNCIAS}

AGUIRREZÁBAL, L.A.N. et al. La intercepción de la radiación lumínica. In: ___. Girassol: aspectos fisiológicos que determinan el rendimiento. Buenos Aires: INTA, 2001. p.1015, 36-50, 73-83.

AGUIRREZÁBAL, L.A.N. at al. Intercepted solar radiation during seed filling determines sunflower weight per seed and oil concentration. Crop Science Society of América, Madison, v.43, n.1, p.152-161, 2003. Disponível em: <https:// www.soils.org/publications/cs/articles/43/1/152>. Acesso em: 03 mar. 2011. doi 10.2135/cropsci2003.1520.

CASTIGLIONI, V.B.R. et al. Fases de desenvolvimento da planta de girassol. Londrina: EMBRAPA-CNPSo, 1997. 24p. (Documentos, 58).

CASTRO, C. de; FARIAS, J.R.B. Ecofisiologia do girassol. In: LEITE, R.M.V.B.C. et al. (Ed.). Girassol no Brasil. Londrina: Embrapa Soja, 2005. p.163-218.

CASTRO, C. et al. Boro e estresse hídrico na produção de girassol. Ciência e Agrotecnologia, Lavras, v.30, n.2, p.214220, 2006. Disponível em: <http://www.scielo.br/pdf/cagro/ v30n2/v30n2a04.pdf>. Acesso em: 03 mar. 2011.

DOSIO, G.A.A. et al. Solar radiation intercepted during seed filling and oil production in two sunflower hybrids. Crop Science Society of América, Madison, v.40, n.6, p.16371644, 2000. Disponível em: <https://www.soils.org/publications/ cs/articles/40/6/1637>. Acesso em: 03 mar. 2011.

ERDEM, T.; DELIBAS, L. Yield response of sunflower to water stress under tekirdag conditions. Helia, Tekirdag, v.26, n.38, p.149-158, 2003 . Disponível em: <http:// www.doiserbia.nb.rs/img/doi/1018-1806/2003/101818060338149E.pdf>. Acesso em: 03 mar. 2011. doi: 10.2298/ HEL0338149E.

FERREIRA, D.F. SISVAR software: versão 5.0 (Build 67). Lavras: DEX, Universidade Federal de Lavras, 2003. Disponível em: <http://www.dex.ufla.br/ danielff/softwares.htm>. Acesso em: 15 out. 2011.

GAZZONI, D.L. Óleo de girassol como matéria-prima para biocombustíveis. In: LEITE, R.M.V.B.C. et al. (Ed.). Girassol no Brasil. Londrina: Embrapa, 2005. p.145-161. 
HARRIS, H.C. et al. Influence of temperature on oil content and composition of sunflower seed. Australian Journal of Agricultural Research, Melbourne, v.29, p.1203-1212, 1978. Disponível em: <http://www.publish.csiro.au/paper/ AR9781203.htm>. Acesso em: 10 mar. 2011. doi:10.1071/ AR9781203.

IAPAR. Instituto Agronômico do Paraná. Cartas climáticas do Paraná. Disponível em: <http://www.iapar.br/Sma/ Cartas_climaticas>. Acesso em: 01 abr. 2009.

IZQUIERDO, N.G. et al. Weight per grain, oil concentration, and solar radiation intercepted during grain filling in black hull and striped hull sunflower hybrids. Crop Science Society of America, Madison, v.48, p.688-699, 2008. Disponível em: $<$ http://crop.scijournals.org/cgi/content/full/48/2/688>. Acesso em: 17 ago. 2010.

MERCAU, J.L. et al. On-farm assessment of regional and seasonal variation in sunflower yield in Argentina. Agricultural Systems, Amsterdam, v.67, n.2, p.83-103, 2001. Disponível em: <http://www.sciencedirect.com/science/article/B6T3W41Y837G-2/2/51881e034c339447caa2dfe3d8f7eeb7>. Acesso em: 03 mar. 2011. doi: 10.1016/S0308-521X(00)00048-2.

PIMENTEL-GOMES, F.; GARCIA, C.A. Análise de grupos de experimentos. In: _ ; _ (Ed). Estatística aplicada a experimentos agronômicos e florestais. Piracicaba: FEALQ, 2002. p.169-191.
SANTOS, H.G. et al. Sistema brasileiro de classificação de solos. 2.ed. Rio de Janeiro: Embrapa Solos, 2006. 306p.

SHIKAMURA, S.E. Estatística II. Curitiba: Departamento de Estatística, UFPR, 2006. Disponível em: <http://leg.ufpr.br/ silvia/CE003/node74.html>. Acesso em: 31 jul. 2008.

SMIDERLE, O.J. et al. Adubação nitrogenada, espaçamento e épocas de semeadura de girassol nos cerrados de Roraima. In: EMBRAPA-CNPSo: Resultados de pesquisa da EMBRAPA Soja - 2001: girassol e trigo. Londrina, 2002. p.24-29.

SMIDERLE, O.J. et al. Avaliação de cultivares de girassol em savana de Roraima. Acta Amazônica, v.35, n.3, p.331-336, 2005. Disponível em: <http://acta.inpa.gov.br/fasciculos/353/BODY/v35n3a03.html>. Acesso em: 10 mar. 2011.

UNGARO, M.R.G. et al. Influência da temperatura do ar na composição de aquênio de girassol. Pesquisa Agropecuária Brasileira, Brasília, v.32, n.4, p.351-356, 1997. Disponível em: $<$ http://webnotes.sct.embrapa.br/pab/pab.nsf/ 4 b $9327 \mathrm{f} \mathrm{c} \mathrm{a} 7 \mathrm{f}$ a c c d e 032564 c e $004 \mathrm{f} 7$ a 6 a/ 4e6f3ff6b18ab268032565f8005f40d7?OpenDocument>. Acesso em: 10 mar. 2011.

VEGA, A.J.; HALL, A.J. Efects of planting date, genotype, and their interactions on sunflower yield - I. Determinants of oilcorrected grain yield. Crop Sciense Society of America, Madison, v.42, p.1191-1201, 2002. Disponível em: <https:// www.soils.org/publications/cs/articles/42/4/1191>. Acesso em: 10 mar. 2011. doi: 10.2135/cropsci2002.1191. 